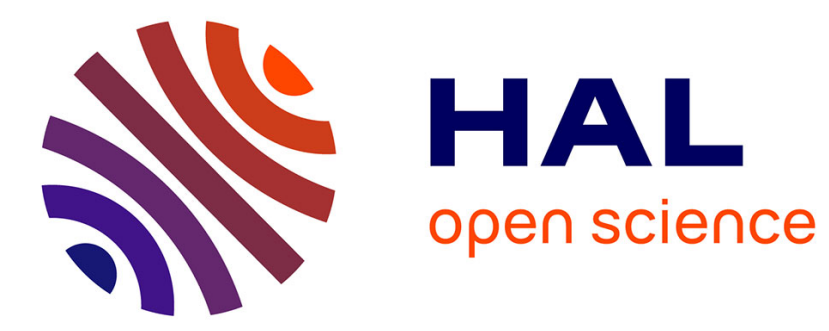

\title{
Thermodisplacement imaging of silicon membranes
}

\author{
J.I. Burov, D.V. Ivanov
}

\section{To cite this version:}

J.I. Burov, D.V. Ivanov. Thermodisplacement imaging of silicon membranes. Journal de Physique, 1986, 47 (4), pp.549-552. 10.1051/jphys:01986004704054900 . jpa-00210234

\section{HAL Id: jpa-00210234 https://hal.science/jpa-00210234}

Submitted on 1 Jan 1986

HAL is a multi-disciplinary open access archive for the deposit and dissemination of scientific research documents, whether they are published or not. The documents may come from teaching and research institutions in France or abroad, or from public or private research centers.
L'archive ouverte pluridisciplinaire HAL, est destinée au dépôt et à la diffusion de documents scientifiques de niveau recherche, publiés ou non, émanant des établissements d'enseignement et de recherche français ou étrangers, des laboratoires publics ou privés. 


\title{
LE JOURNAL DE PHYSIQUE
}

Classification

Physics Abstracts

$65.70-42.60 \mathrm{~K}-81.70$

\section{THERMODISPLACEMENT IMAGING OF SILICON MEMBRANES}

\author{
J.I. BUROV and D.V. IVANOV \\ Department of Solid state Physics, Faculty of Physics, \\ 5 Anton Ivanov Blvd., Sofia 1126, Bulgaria
}

(Reçu le 8 octobre 1985, accepté le 3 janvier 1986)

Résumé.- Des ondes thermoélastiques, excitées par échauffement Joule de couches minces métalliques, ont été utilisées pour restituer les profils compliqués des membranes de silicium, utilisées pour la fabrication de capteurs, d'actionneurs et d'élements sélectifs de fréquence. Le déplacement et la fréquence étant déterminées avec une précision de $5 \%$, on peut déterminer l'épaisseur de la membrane avec une précision de $2,5 \%$.
Abstract. - Thermoelastic waves excited by means of Joule heating in thin metallic layers were used for visualizing the complex profiles of silicon membranes applied in fabrication of sensors actuators and frequency selective elements. Provided that the displacement and the frequency are determined with an accuracy of $5 \%$, then an accuracy of $2.5 \%$ in determining the membrane's thickness can be obtained.
Recently small-displacement measurement technique have made considerable progress mainly as a result of the multiple applications in gravitational waves'detection [1], noncontact measurement of surface acoustic waves [2], nondestructive testing $[3,4]$, photoacoustic spectroscospy and $\mathrm{mi}-$ croscopy $[4,5]$, etc. A new application of this technique in the field of thermodisplacement imaging is presented in this paper. Thermoelastic waves excited by means of Joule heating in thin layers were used for visualizing the complex profiles of silicon membranes used in the fabrication of sensors, actuators and frequency selective elements [6]. We used an one-arm phase-optical bridge [3] for measuring the thermoeleastic displacements. The samples (which we worked on) were polished, $250 \mu \mathrm{m}$ thick (001)-cut Si plates. Thin membranes of 25 $\mu \mathrm{m}$ with different geometrical shapes (Fig. 1b) were obtained through selective etching. Narrow $330 \mu \mathrm{m}$ Cr paths at a distance $15 \mu \mathrm{m}$ one from the other with total ohmic resistance of $100 \Omega$ were evaporated on the opposite side of the plate that was also polished. We switch in series to them pulse voltage $U$ with frequency $\Omega$. The Joule heat released in the $\mathrm{Cr}$ layers engenders thermoelastic waves in the silicon sample. The sample is fastened firmly to the movable support supplied with micrometric screws giving the possibility of shifting the table in three perpendicular directions. The magnetic field of a ferrite cylindrical core is shut off by means of a round iron membrane with a hole in the centre. A flat concave lens with curvature radius of $1 \mathrm{~cm}$ is attached to the membrane as it is shown in figure 1a. Two coils are placed in the pot-type core. One of them is supplied with a sawtooth voltage with very low frequency [3] and the other one is supplied with a DC tension for precise regulation of the distance between the lens and the surface of the sample. For frequencies below $100 \mathrm{kHz}$ the normal component of the vibration was measured by means of a low-frequency synchronous-selective technique as in reference [7]. Above $100 \mathrm{kHz}$ however in order to 


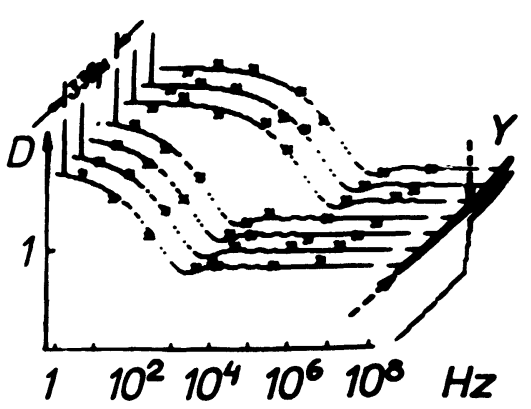

Fig. 2a.- Frequency dependence of the parameter D. $x$ : experimental, theoretical

and $\alpha$ is the coefficient of the linear thermal expansion of $\mathrm{Si}$.

As it is seen in figure $2 a$ the values of $D$ as function of $\Omega$ obtained experimentally and theoretically coincide well. For that reason the relation (1) is used further for determining the thickness $L(y, z)$ in a given point $(y, z)$ and for restoring the vertical section of the Si-sample.

Experimentally that was accomplished by scanning the sample and by measuring the thermodisplacement amplitudes $\mathrm{d}_{0}(\Omega)$ and $\mathrm{d}_{\mathrm{o}}\left(\Omega_{\infty}\right)$ for $\Omega=500 \mathrm{~Hz}$ and $\Omega_{\infty}=$ $4 \times 10^{6} \mathrm{~Hz}$ in all points at a distance of 240 $\mu \mathrm{m}$ one from the other. the three-dimensional distribution of the thickness $L(y, z)$ calculated according to (1) is shown in figure $2 \mathrm{~b}$. We assumed a Gaussian distribution of the measured values in every point and we used the middle value as the most probable.

The measurement of the plate and the membrane thickness with the help of an optical comparator shows a good coincidence within $3 \frac{8}{8}$ with the described method. The absolute error $\Delta L / L$ of the method can be obtained numerically by solving the equation (1) having in mind the accuracies with which the thermoelastic displacements and the frequency can be determined.

If the accuracy with which the displacement and the frequency can be determined is 5 o one can obtain an accuracy for the thickness $L$ of $2.5 \%$.

For imitating the real situation during the technological process of etching measurements of the profiles and the thickness of samples immersed in different liquids transparent for $\mathrm{He}-\mathrm{Ne}$ laser such as water, oil and paraffin were accomplished. The results differ from those obtained without liquids within several percent.

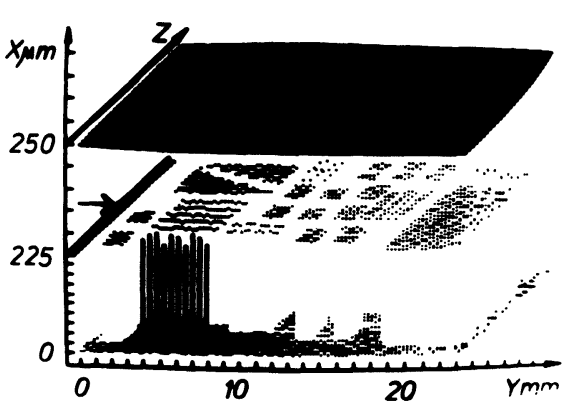

Fig. 2b.- Three-dimensional computer reconstruction of the silicon sample

The high sensitivity of the thermoelastic displacement determination $\left(\sim 10^{-13}\right.$ m) requires a low threshold value of the variable Joule component (respectively the temperature component) exciting the thermoelastic waves. The calculation shows that for si-sample this value is of the order of $10^{-10}{ }^{\circ} \mathrm{C}$. Therefore the measurement of the thickness, the profile and their changes in time can be accomplished during the technological operation of etching of the plate without influencing the processs because of the low threshold value of the temperature component necessary for thermoelastic wave generation.

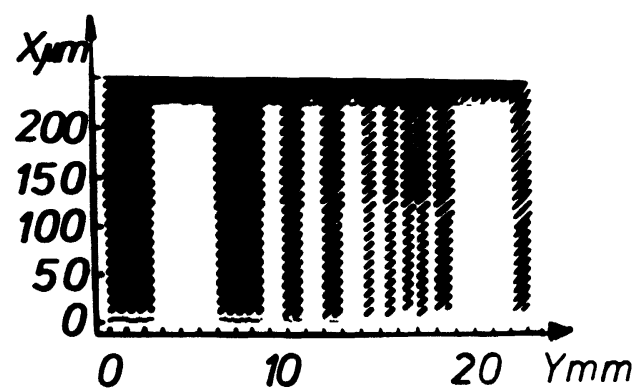

Fig. 2c.- Cross section of the silicon sample along the $\mathrm{Y}$-axis

In conclusion we can conclude that thermoelastic displacement microscopy is good nondestructive mean of measuring and controlling the thickness and the profiles of homogeneous Si-plates with thickness greater than $1 \mu \mathrm{m}$. This can be accomplished during the technological process itself. In this way the kinetics of the process can be controlled and also it can be programmed and automated completely. The considered method becomes entirely noncontact if the energy of the heating laser beam is absorbed by the Si-sample only. 


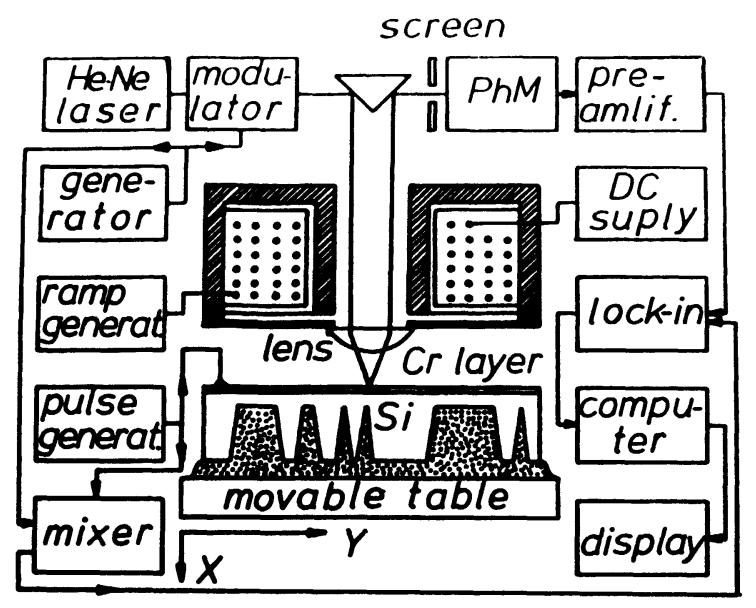

Fig. 1a.- Experimental setup

use the same low-frequency technique the principle of non-linear optical mixing of two vibrations with close frequencies was applied as it is shown in reference [3]. For that reason the intensity of $40 \mathrm{~mW} \mathrm{He}-$ $\mathrm{Ne}$ laser was modulated with frequency $\omega$ close to the thermoelastic wave frequency $\Omega$ and with a modulation depth $b$. The beam reflected by the concave side of the lens and by the $\mathrm{Cr}$ layer interfere and form Newton fringes on the screen. The orifice in the screen lets only the central Newton fringe out to the photomultiplier. The normal component of the thermoelastic displacement created by the periodic Joule heating with frequency $\Omega-\omega$ provokes changes in the intensity of the central Newton fringe. The AC voltage amplitude $U_{\text {eff }}(\Omega-\omega)$ of the photomultiplier with a frequency $\Omega-\omega$ was measured with the help of a synchronous voltmeter.

The normal component amplitude $d_{0}(\Omega)$ of the surface vibrations with frequency $\Omega$ can be calculated according to the relation [3] :

$$
d_{o}(\Omega)=\lambda U_{e f f}(\Omega-\omega) / \pi B \sqrt{2}\left(U_{m a x}-U_{m i n}\right)
$$

where $U_{m a x}-U_{m i n}$ is the interference contrast in volts. $d_{0}$ depends on the thermal and thermoelastic properties of the sample as well as on the sample profile. In figure $2 \mathrm{a}$ the asterisks mark the frequency dependence of the normalized product $D=d_{0}(\Omega) \Omega /$ $d_{0}\left(\Omega_{\infty}\right) \Omega_{\infty}$ measured in several points of one

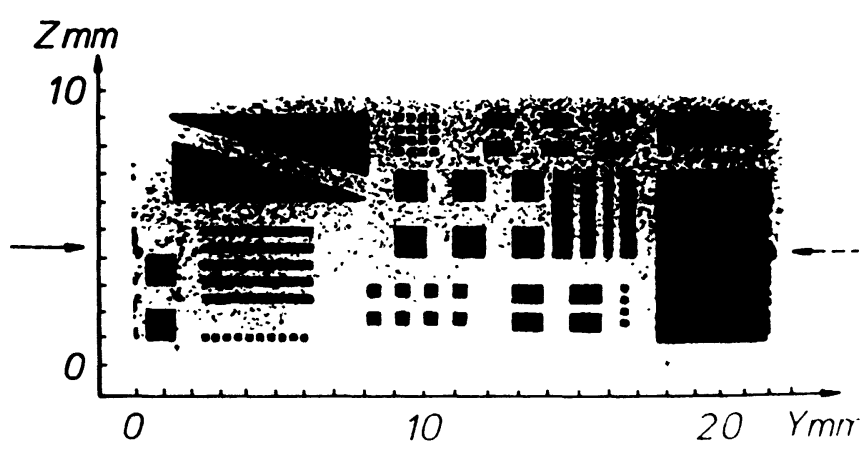

Fig. 1b.- A silicon plate with different membrane shapes

and the same line along the $Y$-axis as it is shown in figure $1 \mathrm{~b}$ with a dotted arrow. Here $d_{0}\left(\Omega_{\infty}\right)$ stands for the thermoelastic wave amplitude at sufficiently high frequencies.

At these frequencies the thermodiffusion length $\mu=1 / \beta=(2 \mathrm{k} / \mathrm{c} \rho \Omega)^{1 / 2}$ is smaller than the thickness $L(Y, z)$ of the Sisample, i.e. for a thermoelastic wave with a frequency $\Omega_{\infty}$ the Si-sample has an infinite thickness and the condition $\exp (-\beta L)=0$ is satisfied. $k=150 \mathrm{Wm}$.deg, $\rho=2420$ $\mathrm{kg} / \mathrm{m}^{3}$ and $\mathrm{c}=700 \mathrm{~J} / \mathrm{kg} \cdot \mathrm{deg}$ are the thermal conductivity, the density and the specific heat of the si-sample respectively. In the same figure the continuous line marks the theoretically calculated frequency dependence $D$ according to the relation :

$$
\begin{gathered}
D=\{1+\exp [-2 \beta L 6(y, z)]+ \\
2 \exp [-\beta L(y, z) \cos [\beta L 6(y, z)]]\}^{1 / 2}
\end{gathered}
$$

This relation is obtained after the integration $d_{0}=\alpha \int_{0} T=(x, t) d x$ of the variable component in the case of one-dimensional temperature distribution in the form of plane thermal waves [8]

$$
\begin{aligned}
T(x, t)= & J_{0} \exp (-\beta x)[\cos (\Omega t-\beta x)+ \\
& \sin (\Omega t-\beta x)] / 4 k \beta
\end{aligned}
$$

where $J_{0}=U^{2} / R$ is the amplitude of the evolved variable Joule heat in the $\mathrm{Cr}$ layer 


\section{REFERENCES}

[1] R.L. Forward, Phys. Rev. D, 17, (1978) 379

[2] R. De La Rue, R.F. Humphryes, I.M. Mason, E.A. Ash, Proc. IEE, 119 , (1972) 117

[3] M. Borisov, K. Bransalov, J. Burov, Jap. J. Appl. Phys. 15, (1976) 797

[4] K.F. Etzeld, RCA Rev. 43, (1982) 95

[5] L. Konstantinov, V. Hinkov, J. Burov, J. Phys. C : Solid State Phys. 14, (1981) 1799
[6] IEEE Trans. Electr. Devices ED-29 (1982) (Special issue on solid state sensors, actuators and interface electronics).

[7] M. Borisov, J. Burov, Electr. Lett. 9, (1973) 355

[8] H.S. Carslaw, J.C. Jaeger, Conduction of Heat in Solids, (Clarendon Press, Oxford), 1959. 